ISSN 2075-471X

www.mdpi.com/journal/laws/

\title{
Communication
}

\section{The State of Contracts Scholarship in the United States}

\author{
Ethan J. Leib \\ Fordham Law School, 140 West 62nd Street, New York, NY, 10023, USA; \\ E-Mail: ethan.leib@law.fordham.edu
}

Received: 4 September 2012; in revised form: 6 October 2012 / Accepted: 11 October 2012 /

Published: 22 October 2012

\begin{abstract}
This paper reports on the state of contracts scholarship in the United States, utilizing two methods of approximating where scholarship has focused since 2007 and where it is headed in the future.
\end{abstract}

Keywords: contracts; methodology; common law; statutory law; regulation

\section{Introduction}

I used two imperfect methodologies to get a sense of where contracts scholarship has been since 2007-and where it is headed. First, I compiled a bibliography of contracts articles published in a set of the nation's widely respected law journals [1]. Articles were chosen by looking for "Contracts" as a subject in the Index to Legal Periodicals (Ebsco) as well as searching tables of contents of the relevant journals [2]. Once that database was complete (it has 93 entries), I got a feel for the subject matters these articles treated and developed a survey instrument to distribute to the scholars and teachers who participate in the American Association of Law Schools contracts listserv. Looking at a sample of the best law journals can only be an approximation of what is going on in the field: the biases of the journals, their editors, and their selection processes cannot stand-in for the state of scholarship today, even if it has a direct effect on the direction scholarship takes. Reaching out more broadly to scholars directly - many of whom publish in and read in other journals-helped me identify what might be going on within the hundreds of other journals publishing contracts scholarship that were not directly observed. I received 78 replies to my survey, though not all respondents answered every question [3]. This brief comment reports the results of these inquiries: both the survey of the scholarship and the survey of scholars. 


\section{Methodology in Contracts Scholarship}

In my review of published articles since 2007, four methodologies predominated: doctrinal analysis, economic analysis (understood as modeling and economic reasoning), philosophical analysis, and empirical investigations (understood as experimentation, case studies, and/or dataset collection/exploration). It was no surprise that respondents in my survey identified all four as "mainstream," though they did so in varying degrees. The vast majority of respondents see doctrinal analysis as "mainstream" (57 of 76 answering the question) and the fewest (22 of 76) see empirical work as "mainstream;" economic analysis was also deemed "mainstream" by more than half of respondents (48 of 76) - and philosophical work was deemed mainstream by just more than half, too (39 of 76). In my direct observations [4], 29 articles were mostly doctrinal; 30 were mostly economic; 19 were mostly empirical; and 15 were mostly philosophical.

When respondents were asked about what is "hot" in the world of contracts scholarship (74 of the 78 answered this question), doctrinal analysis - though concededly "mainstream"-was essentially deemed uncool: only 5 respondents named it, even though they were free to choose multiple entries for "hot" methodologies. Although it was not surprising to me that a strong majority identified empirical work as "hot" (49 of the 74), it surprised me that it still is not deemed "mainstream". Economic analysis was considered "hot" by 26 of 74 respondents; philosophical analysis was considered "hot" by only 19 of 74 respondents. Again, my direct observation of the articles themselves in top journals revealed as much doctrinal work as economic work - and essentially the same amount of empirical work as there is philosophical work. I represent these findings graphically in Table 1.

Table 1. Prevalent Methodologies in Contracts Scholarship.

\begin{tabular}{|l|c|c|c|}
\hline Methodology & $\begin{array}{c}\text { Number of direct } \\
\text { observations (n=93) }\end{array}$ & $\begin{array}{c}\text { Number of respondents } \\
\text { deeming method } \\
\text { "mainstream" }(\mathrm{n}=76)\end{array}$ & $\begin{array}{c}\text { Number of respondents } \\
\text { deeming method "hot" } \\
(\mathrm{n}=74)\end{array}$ \\
\hline Doctrinal & 29 & 57 & 5 \\
\hline Economic & 30 & 48 & 26 \\
\hline Empirical & 19 & 22 & 49 \\
\hline Philosophical & 15 & 39 & 19 \\
\hline
\end{tabular}

Apart from basic questions of methodological approach, there is also a divide among contracts scholars with respect to whether they see contracts scholarship as a unified field or as a fragmented field, focused instead on particular transactional contexts (sales, employment contracts, insurance contracts, firm-to-firm contracts, etc.). Although there was likely a time when contract scholars thought they were working in a unitary field, $65 \%$ of my respondents reported that they believe that the field is "mostly fragmented into studies of specific contractual contexts." It has long been believed by "relationalists" within the field that the future of contract law is in further fragmentation rather than grand unified field theory - and it appears that scholars see that development coming to pass [5].

This survey finding sits in some tension with my sample of scholarship, which evidenced more "unified" work (49 of 93) than "fragmented" work (44 of 93). I suspect the finding in the database of articles is driven by editor selection preferences - and that my respondents are right that work is leaning "fragmented" overall. Whether or not that is a function of the "hotness" of empirical work is 
hard to say, though a turn to empirical work would almost certainly require a turn to specific contractual contexts. It takes a long time to use induction from solid empirical studies of specific contexts to get to unified field theory. It is also very possible that narrowing the database to articles that are specifically about "contracts" as such produces an unsurprising result that the database is populated by "unified" work; finding more "fragmented" work would have probably required searching for articles with a broader set of search terms. The survey respondents' supplemental information about what is going on in the field is probably more reliable on this dimension than is the scholarship database, for these reasons.

\section{The Substance of Contracts Scholarship}

As for what is being written about as a matter of substance, respondents were asked to identify areas within contract scholarship which have produced fresh insights since 2007. Essentially half of the respondents $(n=69)$ identified the psychology of contracting (35) and arbitration (33) as the most fertile areas for interesting new work in the field. Other quite popular choices for the discovery of fresh insights include scholarship on standard form contracts (29) and power relationships within contractual arrangements (29). A few other substantive areas of inquiry also had more than 20 respondents thinking that fresh insights have been produced since 2007: drafting and contractual design (22), interpretation (21), and remedies (including efficient breach) (21). Areas where respondents were seemingly underwhelmed with the scholarship in the area since 2007 included, inter alia, reliance accounts of contractual liability (6), consent accounts of contract (8), implications of contract for distributive justice (12), and promissory theory (13). It seems clear that reliance and consent theory were generated prior to 2007 and that little new work has been written in these domains. However, there is plenty of work in the database of articles that would broadly be considered to fall under the rubric of "promissory theory" - and respondents seem not to think this work is full of fresh insight.

In light of the general attention recently given to statutes and regulation within legal education in the US [6], it is also worth asking whether the scholarship in contracts has attempted in any more substantial way to integrate themes from the legislation and regulation field. Given that there is likely a movement toward fragmentation within contracts scholarship, that many transactional areas are heavily regulated, and that even the broad area of sales has been codified for decades in the Uniform Commercial Code, one might expect to see more effort to bring insights from the legislation and regulation field to bear on contract analysis. Still, 65\% of my sample (76 respondents answered the question) claimed that no effort has been made to bring the study of legislation and regulation within the contracts umbrella. That finding was confirmed in my sample of articles, with 72 of 93 largely being common law driven and 21 of 93 being mostly statutory. Given the agreement between survey result and database result, I am inclined to think the contracts field has a way to go in integrating the lessons of legislation and regulation into mainstream contracts work. Yet, it is also possible that the some highly regulated areas of contracts have branched off from the field (into insurance, lending, and commercial law), so contracts scholars are insulated from them - and searches for contracts articles do not reveal much of this writing. 


\section{The Future of Contracts Scholarship}

It is, of course, very hard to identify where the future of the field is headed. So much depends on which cases make the papers and/or reach the Supreme Court: arbitration is much in the news, which certainly helps contracts scholars decide to write about it. The future of the field is also affected by what famous professors decide to focus upon within their research agenda, which probably sets the agendas of others, including their students who then become professors. And movements in other fields or disciplines or countries [7] which could affect the development of scholarship cannot be easily anticipated.

When my respondents were asked where they expect to see fresh insight over the next five years, they chose mostly the same areas in which they had seen insights since $2007(n=66)$ : the psychology of contracting (35), arbitration (32), drafting and contract design (32), and standard form contracts (30). They also expect to see fresh work in power relationships within contractual arrangements (22) and the voluntariness of contractual relations (20). However, respondents were not as optimistic that they would see much of interest in interpretation (14) and remedies (12).

\section{Conclusions}

The metrics used here to divine the state of the field are hugely imperfect. They measure a snippet of a thin slice of time. And they are deeply parochial, focused as they are on what Americans are doing (though foreigners publish in American law reviews commonly and the AALS listserv has its share of international scholars of contract law). Future work, should there be interest in pursuing these questions more rigorously, ought to use better methods to understand what is being published, where, and why.

However, the limited data still generate a picture about where contract scholars have gone and where they are going. Although empirical scholarship may seem to be all the rage, economic and doctrinal work appear to continue to occupy more of the field. Psychological work and studies of arbitration are producing fresh insight in the mind of scholars - and are predicted to continue to do so. Scholars have not yet seemed to integrate the lessons of legislation and regulation into contracts scholarship, but they have, in some measure, appeared to let go of a unified contract theory, enabling the field to fragment itself into transactional context.

I do not know if the state of the field is strong: many of my respondents felt frustrated with the slow pace of growth in contracts scholarship. However, my sense of it is that we are learning some new things and letting some old fixations go. That may be all that can reasonably be expected of a centuries-old field, one populated with deeply human questions about the way we do and should interact, exchange, and transact with one another.

\section{Acknowledgments}

Thanks to Fordham University for financial support, to Larry Abraham, Max Liporace, and Emily Wolf for research support, and to Fordham's contracts teachers for discussions about this comment. 


\section{References and Notes}

1. I surveyed the following law journals: WM. \& MARY L. REV., MICH. L. REV., DUKE L.J., VA. L. REV., J. LEGAL STUD., LAW \& SOC'Y REV., N.Y.U. L. REV., LAW \& SOC. INQUIRY, NW. U. L. REV., TEX. L. REV., YALE L.J., CORNELL L. REV., HARV. L. REV., U. PA. L. REV., U. CHI. L. REV., COLUM. L. REV., VAND. L. REV., S. CAL. L. REV., CALIF. L. REV., STAN. L. REV. The class of journals I selected sought to represent journals that would conventionally be regarded as very good placements by most law professors in the US. I included law reviews whose articles are chosen by law students as well as peer-reviewed journals. The different article selection processes between student-edited reviews and peer-review journals - as well as the methodological orientations of the peer-review journals - probably creates various biases in the database of articles, which would help explain some of the findings reported here.

2. The method of populating the database obviously affects ultimate results. Articles primarily about corporate mergers, for example, may be classified as "contracts" for some purposes but would have been excluded from the database. Using the classification in the proprietary database and supplementing with common sense undoubtedly creates a risk of bias.

3. Carol Chomsky, the moderator of the listserv estimates that about 550 contracts scholars receive email from the list; that estimate suggests a $14 \%$ response rate to the survey. I did not collect any identifying information from my respondents. Because I wanted to maximize the response rate and maintain anonymity completely in this informal context, I kept the survey very short. A more elaborate methodology would have collected more information from respondents to learn more about how gender, age, and institutional affiliation can predict how one perceives the field. That is a direction for future research.

4. I asked two coders to categorize each of the 93 entries with only one methodology. When the coders agreed about the methodology that dominated an article's inquiry, I accepted their assessment; when they disagreed, I used my personal judgment.

5. See generally Jay Feinman. "Relational Contract Theory in Context." Northwestern University Law Review 94 (2000): 737.

6. See Ethan J. Leib. "Adding Legislation Courses to the First-Year Curriculum.” Journal of Legal Education 58 (2008): 166.

7. My respondents were generally unaware of contracts scholarship overseas (even the few who claimed to know something about contract law elsewhere had contradictory things to say about mostly European contracts scholarship). And in my sample of 93 articles, only 6 dealt with international themes. Maybe all law is local—as one of my respondents wrote — so it shouldn't be concerning that there is very little transnational conversation among contracts scholars. But one is hard-pressed to believe that American contracts scholarship will be hermetically sealed off from foreign contract scholarship for too long. Thanks to the efforts of one new journal(!), we might see better cross-fertilization in the coming years.

(C) 2012 by the author; licensee MDPI, Basel, Switzerland. This article is an open access article distributed under the terms and conditions of the Creative Commons Attribution license (http://creativecommons.org/licenses/by/3.0/). 